\title{
Fever with vesicular rash in an adult
}

\author{
Hong Kong Med J 2014;20:264.e3-4 \\ DOI: $10.12809 / \mathrm{hkmj} / 134018$
}

Prashant Nasa *, Ankur Gupta, Shakti Jain, Kishore Mangal

A 30 year-old man was admitted with fever and myalgia for 4 days, rashes over abdomen and forehead for 2 days (Fig 1), and breathing difficulty for 1 day in January 2013. There was a history of similar rashes affecting his wife 7 days earlier. On examination, he was tachypnoeic (respiratory rate, 24 breaths/min), conscious, and oriented. He had a papulo-vesicular rash on the forehead, scalp, and trunk but the extremities were spared. Laboratory investigations revealed thrombocytopenia (platelet counts, $30 \mathrm{x}$ $10^{9} / \mathrm{L}$ ), deranged liver function tests (serum bilirubin $4.6 \mathrm{mg} / \mathrm{dL}$, direct bilirubin $2.9 \mathrm{mg} / \mathrm{dL}$, aspartate transaminase $1316 \mathrm{IU} / \mathrm{L}$, alanine transaminase 989 IU/L, alkaline phosphates $116 \mathrm{IU} / \mathrm{L})$. The chest $\mathrm{X}$-ray showed no gross abnormality and the smear of skin scrapings showed multinucleated epithelial giant cell (Tzanck cells), abundant erythrocytes, and sporadic leukocytes (Fig 2). Aerobic bacterial culture of a swabbed vesicle fluid was sterile. The history and characteristic pattern of the vesicular rash on the scalp and abdomen with no history of childhood immunisation against chickenpox clinched the diagnosis of chickenpox. The diagnosis is primarily clinical. Confirmation requires either viral culture of the vesicular fluid or direct fluorescent antibody testing of serum, ${ }^{1}$ but these tests are not readily available. Smear examination showing Tzanck cells in vesicle fluid may be positive in chicken pox, but also occurs in herpes simplex, herpes zoster, cytomegalovirus infection, and even pemphigus vulgaris. ${ }^{1}$ The differential diagnosis in our case was severe Chicken pox, disseminated herpes simplex infection, disseminated herpes zoster infection, drug eruptions, and pityriasis lichenoides et varioliformis acuta. However the clinical history (including family and vaccination history) favoured severe chickenpox.

Chickenpox is rarely fatal, although it is generally more severe in adults than children; those who are pregnant or immunocompromised have more severe forms of the disease. ${ }^{2}$ Serious manifestations of varicella-zoster virus (VZV) infection include pneumonia, hepatitis, and encephalitis. ${ }^{2,3}$ The standard treatment for severe adult VZV infection with or without involvement of vital organs entails early recourse to intravenous antivirals such as acyclovir. Whether severe or not, meticulous skin care, hygiene, and droplet precautions should be implemented to prevent cross-transmission to others till the patient's lesions desquamate.

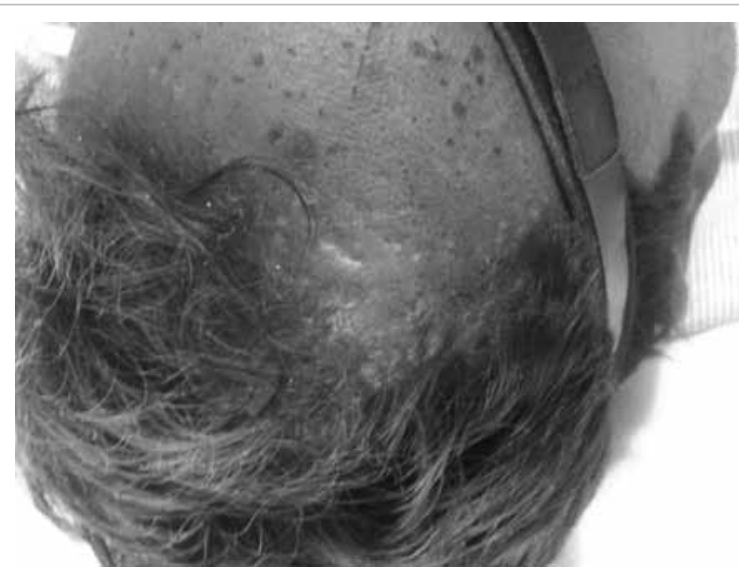

FIG I. A rash over the forehead and scalp

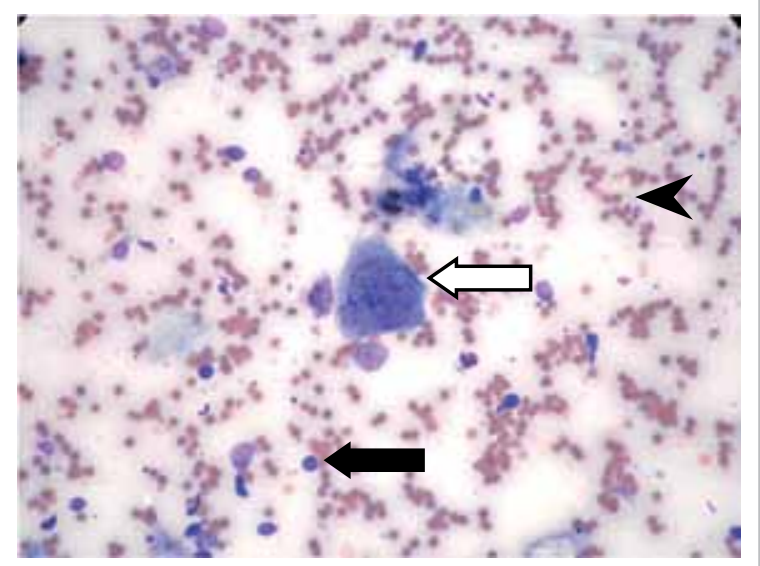

FIG 2. Giemsa stain of skin scrapings from the base of a vesicle showing a multinucleated epithelial giant cell (Tzanck cell) [white arrow], abundant erythrocytes (black arrowhead), and sporadic leukocytes (black arrow) [Giemsa stain; original magnification, $x$ 200]

${ }^{1}$ P Nasa, MD, FNB

${ }^{2}$ A Gupta, MD, DM

${ }^{3} \mathrm{~S}$ Jain, $\mathrm{MD}$

${ }^{1} \mathrm{~K}$ Mangal, MD, IDCCM

Departments of ${ }^{1}$ Critical Care Medicine, ${ }^{2}$ Nephrology, and ${ }^{3}$ Microbiology, Max Super Speciality Hospital, Shalimar Bagh, New Delhi 110088, India

* Corresponding author: dr.prashantnasa@hotmail.com 


\section{References}

1. Herpesviruses: Varicella zoster virus (VZV). In: Shors T Understanding viruses. 2nd ed. Burlington, MA: Jones \& Bartlett; 2011: 459.

2. Maggi U, Russo R, Conte G, et al. Fulminant multiorgan failure due to varicella zoster virus and HHV6 in an immunocompetent adult patient, and anhepatia. Transplant Proc 2011;43:1184-6.

3. Mohsen AH, McKendrick M. Varicella pneumonia in adults. Eur Respir J 2003;21:886-91. 